\title{
A UTILIZAÇÃO DO CONCEITO E MÉTODO DA FORMAÇÃO SOCIOESPACIAL QUANTO AO ESTUDO DAS PEQUENAS CIDADES
}

\author{
THE USE OF THE CONCEPT AND METHOD OF SOCIO-SPATIAL FORMATION IN THE STUDY \\ OF SMALL CITIES
}

Franciele Miranda Ferreira Dias*

*Doutoranda no PPG em Geografia, UEL - franciele.ferreiradias@gmail.com

Recebido em 07/03/2019. Aceito para publicação em 20/03/2019.

Versão online publicada em 26/04/2019 (http://seer.ufrgs.br/paraonde)

\begin{abstract}
Resumo:
0 tema pequenas cidades tem paulatinamente despertado o interesse dos pesquisadores, em decorrência das mudanças derivadas da complexificação das relações econômicas e sociais e quanto ao papel que esse tipo de cidade tem desempenhado na rede urbana a qual se insere. A fim de compreender qual o papel que as pequenas cidades desempenham na rede urbana, analisa-se a perspectiva teórica calcada no paradigma da Geografia Crítica, cujo conceito e método empregado pauta-se na formação socioespacial de Santos (1979). Assim, o presente trabalho, objetiva discutir o conceito e método citados, em relação ao estudo da inserção das pequenas cidades na rede urbana. A metodologia empregada no trabalho é a análise das obras que trataram da construção dos elementos relativos à criação do conceito da formação socioespacial resultando na reflexão acerca da aplicabilidade do mesmo, no contexto da pequena cidade.
\end{abstract}

Palavras-chave: Pequenas Cidades, Rede Urbana, Formação Socioespacial

\begin{abstract}
The theme small cities has gradually aroused the interest of researchers, due to the changes derived from the complexification of economic and social relations, as to the role that this type of city has played in the urban network to which it belongs. In order to understand the role that small cities play in the urban network, the theoretical perspective based on the Critical Geography paradigm is analyzed, whose concept and method is based on the socio-spatial formation of Santos (1979). So, the present work aims to discuss the concept and method cited, in relation to the study of the insertion of small cities in the urban network. The methodology used in the work is the analysis of the works that deal with the construction of the elements related to the creation of the concept of the socio-spatial formation resulting in the reflection about the applicability of the same, in the context of the small city.
\end{abstract}

Key-words: Small Cities, Urban Network, Socio-Spacial Formation.

\section{1-Introdução}

O trabalho ${ }^{1}$, pautado no paradigma da Geografia Crítica, considera a Formação Socioespacial como categoria de análise, a qual revela a concreticidade de uma sociedade, qual seja sua origem, evolução e situação atual, de forma geograficamente localizada. Dessa maneira, analisa-se o conceito da

\footnotetext{
${ }^{1} \mathrm{O}$ artigo é parte dos resultados obtidos na tese de doutoramento da autora.
} 
Formação Socioespacial, estabelecido² por Milton Santos em meados da década de 1970. No entanto, a fim de compreender o mesmo, remete-se à análise dos princípios da formação econômica e social, estabelecida por Marx (1983), no prefácio da obra "O Capital" e na obra "A ideologia Alemã" de Marx e Engels (1998), bem como, Lenin (1982), quanto à obra "O Desenvolvimento do Capitalismo da Rússia" por estabelecer o a aplicação da formação econômica e social, quanto ao estudo do país citado.

Também, discute-se o aporte teórico de Mamigonian (1996), cuja análise concluiu que a teoria em tela não deveria restringir-se apenas à aplicação quanto à escala nacional, apresentando assim, novas perspectivas para as discussões relativas à Formação Socioespacial, ao propor múltiplas escalas geográficas de atuação ${ }^{3}$.

Nessa perspectiva, alguns autores têm aplicado a teoria e método da Formação Socioespacial como um elemento auxiliar na compreensão do papel das pequenas cidades, em especial no que tange à rede urbana como recorte geográfico, podendo citar Fresca (2000), Endlich (2006), dentre outros. Dessa maneira, objetiva-se trazer alguns apontamentos acerca de como o conceito e método da formação socioespacial pode ser atrelado ao estudo de pequenas cidades.

\section{2-A construção do conceito e método da formação socioespacial}

Inicialmente, a Formação Econômica e Social, discutida no prefácio de "O Capital" de Marx (1983) apresentava-se como uma opção de método o qual mostrou-se uma possível alternativa quanto às ciências humanas, expondo que a pesquisa deveria atrelar-se ao concreto-dado, ou à síntese das múltiplas determinações, ou seja, aquela realidade existente independente de ser estudada ou percebida. De tal maneira, apresentava-se com um método aplicável às ciências humanas, devendo apreender o todo, a totalidade, possibilitando a compreensão da realidade concreta.

A formação econômica e social de Marx (1983) é constituída pelo aspecto social e econômico, sendo que a formação econômica é uma categoria teórica a qual relaciona-se ao modo de produção. Por sua vez, a formação social diz respeito à evolução diferencial das sociedades, relacionado à produção realizada pelo homem e também às forças externas. Logo, a formação social deve ser apreendida mediante o conhecimento do desenvolvimento histórico ${ }^{4}$ pelo qual passou a sociedade, pois apenas dessa maneira pode-se entender como a mesma se constituiu.

Lenin (1982) resgatou a discussão do conceito e método no que se refere à Formação Econômica e Social ao aplica-la a fim de entender os desdobramentos do capitalismo na Rússia. Nesse estudo, a formação social era atrelada à sociedade do país citado e não à sociedade mundial, portanto, apresentando diferenças quanto à Formação Econômica e Social de Marx (1983), pois Lenin (1982) considerou que a Formação Econômica e Social não existiria caso não fosse em uma sociedade historicamente determinada, assim sendo, não necessariamente mundial, tal qual preconizara Marx (1983).

No entanto, a discussão acerca da Formação Econômica e Social permaneceu sem ser apreciada até meados da década de 1970, voltando a ser tema de interesse através de Sereni (1971), pois esse autor julgou importante os aspectos políticos, culturais e sociais, até então não observados, enquanto influenciadores do desenvolvimento histórico, justificando a necessidade da reflexão em torno da Formação Econômica e Social, bem como a aplicação do método quanto às ciências humanas.

\footnotetext{
${ }^{2}$ Artigo publicado originalmente, em 1977, na revista Antípode e Boletim Paulista de Geografia sob o título de "Sociedade e Espaço - A Formação Espacial como teoria e como método".

${ }^{3}$ Embora seja importante à aplicação da Formação Socioespacial quanto um método de estudo, não discutiremos em razão da extensão da temática, seus desdobramentos atrelados às Combinações Geográficas de CHOLLEY (1964 a e $1964 b$ ).

4 Existem também problemas atrelados à estrita sucessão de tempos históricos, pois os mesmos não apresentavam a possibilidade da existência de modos de produção distintos, conforme apontou Hobsbawn (1985).
}

Para0nde!?, Porto Alegre, v.11, n.1, p.09-16, 2019. http://seer.ufrgs.br/paraonde

Edição Especial: “Geografia e transformações socioespaciais: dinâmicas agrárias e políticas do desenvolvimento regional” 
Logo, o precedente para o desenvolvimento da teoria e método da Formação Socioespacial deu-se a partir do último quartel do século XX, quando se passou a entender que o homem transforma a natureza e a torna um espaço produzido. Assim, a influência da dialética marxista e do materialismo histórico na geografia fez-se latente na Geografia Crítica, a partir da década de 1970. Por sua vez, Santos (1979) buscando um método condizente com o estudo do espaço produzido pelo homem, passou a refletir sobre a temática, construindo assim sua maior contribuição teórica, de acordo com Mamigonian (1996); a construção do método e conceito da Formação Socioespacial.

Dessa maneira, no que tange à ciência geográfica, para Santos (1979), a Formação Econômica e Social não seria capaz de explicar a realidade, pois, embora considerasse uma dada sociedade em um tempo histórico, atrelado ao fator econômico, ou à produção, não relacionava os mesmos com o espaço, e por certo, nem a sociedade existe fora do espaço, nem a produção ocorre fora do mesmo. Portanto, o autor considerava que a sociedade deveria ser compreendida mediante o tempo e também o espaço, ou seja, a totalidade histórica e o desenvolvimento da sociedade.

Deste modo, o autor, ao determinar a adição do espaço ao estudo da Formação Econômica e Social, torna a Formação Socioespacial uma categoria, o qual analisaria a sociedade enquanto uma totalidade em evolução e cujo recorte geográfico seria o Estado-Nação:

A categoria da Formação Econômica e Social é assim extremamente útil ao estudo de uma realidade nacional pelo fato de que não se aplica a uma sociedade precisa, cuja especificidade e particularismo devem ser realçados para que o estudo concreto das realidades autorize depois uma ação concreta (SANTOS, 1979, p. 10).

A inserção da categoria espaço à Formação Econômica e Social de Marx (1983) é justamente o ponto principal da Formação Socioespacial de Santos (1979), pois o autor entendeu que, não existe sociedade a-espacial, ou seja, não vinculada a um espaço, bem como o modo de produção apenas pode ser realizado no espaço, não sendo possível entender a Formação Econômica e Social sem a inserção dessa categoria.

Deste modo, a Formação Socioespacial acaba por analisar a concentricidade de uma sociedade, o que engloba sua gênese, evolução e situação atual, considerando para tal o processo histórico que levou à configuração de um dado momento a ser analisado, sendo a análise de uma realidade concreta, histórica e espacialmente determinada. Assim, conforme apontou Santos (1979), estuda-se uma parte a fim de compreender o todo, ou a totalidade, embora seja um todo em sua fração uma vez que abarca um tempo histórico singular, obtendo-se um conhecimento específico que é válido para um dado momento da evolução daquela sociedade.

Nesse momento, ao inserir a categoria espaço, Santos (1979) determina a formação econômica social e espacial, conforme tornou-se paulatinamente utilizada pelos geógrafos, a Formação Socioespacial ou Formação Sócio-Espacial. Nesse sentido, Mamigonian (1996) ao analisar a aplicação da Formação Socioespacial enquanto um termo, método e conceito já cunhado por Santos (1979), estabeleceu que além da escala nacional dos países, também seria possível a construção de estudos que abarcassem outras escalas de análise.

0 autor compreendeu que há especificidades em todas as escalas geográficas, as quais se pode estudar uma sociedade, implicando, portanto, que a Formação Socioespacial de Santos (1979), seria em realidade a Formação Econômica Social e Espacial, podendo assim ser utilizada como método de pesquisa em estudos regionais. 0 elemento "econômico" insere-se na terminologia discutida aqui por Mamigonian (1996), pois infere a noção de que os aspectos econômicos diferem quanto as diferentes escalas de análise, ou seja, na escala local e regional.

Para0nde!?, Porto Alegre, v.11, n.1, p.09-16, 2019. http://seer.ufrgs.br/paraonde

Edição Especial: "Geografia e transformações socioespaciais: dinâmicas agrárias e políticas do desenvolvimento regional" 


\section{3-A discussão conceitual acerca das pequenas cidades}

A discussão conceitual que permeia o que vem a ser uma pequena cidade mostra-se distante de um consenso uma vez que, há autores que baseiam seus apontamentos teóricos unicamente quanto ao fator populacional, ao passo que outros entendem ser necessário considerar o papel que esse patamar de cidade representa no contexto da rede urbana.

A fim de estabelecer algum direcionamento acerca do que vem a ser uma pequena cidade, é preciso ponderar a questão do tempo, ou seja, em cada período histórico, aquilo que pode ser considerado uma cidade e o respectivo tamanho populacional, apresentam um significado. De acordo com Lencione (2008) considera-se o tempo histórico porque um aglomerado urbano pode ser avaliado como cidade em um período e em outro não, ou seja, os tamanhos das cidades têm significados diferentes em realidades distintas.

Não existindo uma definição consensual do que seria uma pequena cidade nem metodologia aplicável ao estudo das mesmas, nota-se duas opções metodológicas, ou seja, o viés demográfico e aquele no qual a pequena cidade é analisada quanto à influência da Formação Socioespacial e a inserção na rede urbana.

Quanto ao aspecto populacional, o ideário da população diminuta é presente não apenas no contexto acadêmico, mas também no senso comum. Para o IBGE, a cidade é um agrupamento humano que apresenta alguma característica urbana, sendo considerado pelo mesmo órgão governamental para fins estatísticos. Logo, atualmente $84,36 \%$ da população brasileira reside em cidades (IBGE, 2010), sendo um país majoritariamente urbano. Para o órgão governamental citato, as pequenas cidades são aquelas que contam menos de 50.000 habitantes, sendo a maioria dos municípios brasileiros composto por pequenas cidades.

Outro indicativo para o tamanho populacional relativo à pequena cidade, é oriundo do IPEA Instituto de Pesquisa Econômicas Aplicada, no qual as pequenas cidades, a exemplo do que pauta o IBGE, apresentam menos de 50.000 habitantes. No entanto, para o IPEA, as pequenas cidades se subdividem em três grupos por tamanho populacional; sendo o primeiro grupo em cidades de até 10.000 habitantes, o segundo, em cidades de 10.000 a 20.000 habitantes e o terceiro, de 20.000 a 50.000 habitantes.

Contudo, nem todos os autores seguem os números estipulados pelo IBGE e IPEA, dentre eles, Amorim Filho \& Serra (2001) consideram o número inferior a 100.000 habitantes caracterizado como pequena cidade ao passo que Lopes (2009) e Veiga (2002) acreditam que uma pequena cidade não ultrapassa o tamanho populacional de 20.000 habitantes. Oliveira \& Soares (2002), consideram a população entre 2.000 e 20.000 habitantes como relativas às pequenas cidades, e, Bacelar (2009), entende que as pequenas cidades referem-se à população urbana de no máximo 10 mil habitantes.

Para Corrêa (2001) a pequena cidade é caracterizada por um aporte populacional de até 50.000 habitantes, sendo um núcleo de povoamento onde parte da população trabalha em atividades ligadas à transformação, circulação de mercadorias e prestação de serviços, além de ser dotada de função de sede municipal. Portanto, pressupõe uma elementar divisão territorial do trabalho, apoiada na existência de atividades que atendam às necessidades mínimas da população.

Nesse sentido, de acordo com Corrêa (1989), o estudo das pequenas cidades não deve ser isolado do restante da rede urbana, pois a mesma é composta de centros urbanos de diferentes portes, havendo relações econômicas e sociais entre os mesmos. Revela-se ainda que, mesmo que numerosas, as pequenas cidades não são iguais, justamente por suas diferenciações econômicas e sociais resultantes de seus papeis na divisão territorial do trabalho. Por sua vez, Endlich (2006) considera

ParaOnde!?, Porto Alegre, v.11, n.1, p.09-16, 2019. http://seer.ufrgs.br/paraonde

Edição Especial: “Geografia e transformações socioespaciais: dinâmicas agrárias e políticas do desenvolvimento regional” 
ainda que além das diferenças entre as pequenas cidades, há a possibilidade do estabelecimento de relações hierárquicas entre si.

Para Fresca (2010), no que tange as pequenas cidades, podem encontrar-se aquelas com um limite mínimo de complexidade nas atividades urbanas e mesmo aquelas com funções urbanas muito complexas. Portanto, para caracterizar uma cidade como pequena é preciso entender sua inserção na rede urbana ou região e no contexto socioeconômico, a fim de não igualar cidades com populações análogas, mas que apresentam características sociais e econômicas diferentes.

Por certo, é cabível essas divergências, mediante às distintas realidades encontradas no contexto do território brasileiro, uma vez que, entre os próprios estados e regiões brasileiras, têm-se aquelas poucas cidades de porte médio e a presença de uma extensa rede urbana composta de pequenas cidades, encabeçadas pela grande cidade, em geral, a capital do estado. Ou seja, uma cidade com 40 mil habitantes pode desempenhar papeis completamente distintos na rede urbana da Amazônia em contrapartida ao papel que uma cidade de 40 mil habitantes desempenharia no estado de São Paulo, o mais populoso e que apresenta uma série de cidades de porte médio, grandes cidades além da própria metrópole São Paulo.

Dessa forma, estabelece-se que as pequenas cidades devem ser entendidas mediante o papel que ocupam na rede urbana, embora o aspecto populacional não possa ser excluído. Porém, a fim de compreender como a rede urbana estabelece-se, deve-se entender como se deu a gênese dos núcleos urbanos que a compõem, sendo útil para tal finalidade, a associação com a Formação Socieoespacial.

\section{4-A formação socioespacial como conceito e método aplicável ao estudo das pequenas cidades}

Os estudos acerca das pequenas cidades, surgiram efetivamente, a partir da década de 1970, sendo os mesmos, incialmente realizados 5 sob pressupostos metodológicos da Geografia Quantitativa, considerando a localização das cidades como resultado da combinação de variáveis relativas à produção e escoamento, bem como custos de transportes. Assim, as cidades dos mais diferentes portes eram estudadas quanto à rede urbana, porém apresentando-se como itens de um sistema, no qual os elementos eram analisados de forma meramente quantitativa.

Magnani (1971) considerou a localização das cidades e seu papel na rede urbana como resultado da combinação de variáveis relativas à produção, escoamento e custos de transportes. Por sua vez, Geiger (1963) apontou o estabelecimento de uma rede urbana no Brasil bastante heterogênea devido as diferenças no processo de urbanização brasileiro.

Com a complexificação das relações econômicas e sociais resultantes da mundialização do capital, tem-se estudos voltados à novas perspectivas teóricas e metodológicas, buscando analisar as pequenas cidades quanto ao papel que as mesmas desempenham na divisão territorial do trabalho e de forma geral na rede urbana.

Ainda, a melhoria dos meios de transporte observada no Brasil sobretudo após a Segunda Guerra Mundial levou, mesmo que de forma heterogênea, devido às características econômicas e sociais de cada região brasileira, a uma interligação entre campo e cidade, sendo que em muitos casos, a pequena cidade incorporou as técnicas desenvolvidas no campo. Nesse sentido, essas pequenas cidades passaram a atender as demandas locais relativas à comércio e serviços, levando à complexificação no tocante as suas funções. (CORRÊA, 2004).

Assim, as pequenas cidades passaram a apresentar novas dinâmicas econômicas manifestas em novos papeis da divisão territorial do trabalho, representada por uma heterogeneidade quanto às

\footnotetext{
${ }^{5}$ A Nova Geografia ou Geografia Teórico-quantitativa foi prevalente entre a década de 1950 e 1970, pautando-se em análises utilizando métodos matemáticos e estatísticos. Também, procurava substituir o trabalho de campo por mensurações em laboratórios, não sendo proeminentes os aspectos econômicos e sociais (CHRISTOFOLETTI, 1985).
}

Para0nde!?, Porto Alegre, v.11, n.1, p.09-16, 2019. http://seer.ufrgs.br/paraonde

Edição Especial: “Geografia e transformações socioespaciais: dinâmicas agrárias e políticas do desenvolvimento regional” 
atividades econômicas desenvolvidas pelas mesmas não sendo possível caracteriza-las unicamente como local da "reserva de trabalho rural", conforme fora preconizado outrora.

Portanto, o estudo das pequenas cidades mostra-se cada vez mais complexo, pois o objeto de estudo tem tornando-se cada vez mais heterogêneo, sendo que a dinâmica da rede urbana a qual essas cidades são parte, também acaba não mostra-se facilmente explicável, valendo-se portanto, da possibilidade da inserção da Formação Socioespacial quanto ao estudo das mesmas.

Nessa perspectiva, vários autores têm utilizado o conceito de método da formação socioespacial de Santos (1979), atrelando ao aspecto econômico apontado por Mamigonian (1994) com o intuito de estudar a escala local, ou seja, as pequenas cidades no contexto da rede urbana, podendo citar os trabalhos de Casaril (2014), Asalin (2015), Veiga (2014), Bessa (2007), Asalin (2015), dentre outros. Também, diversas discussões têm sido travadas no âmbito do programa de pós-graduação em Geografia da Universidade Federal de Santa Catarina (UFSC) ${ }^{6}$ em parceria com pesquisadores de outras instituições de ensino brasileiras.

Dessa forma, conforme Mamigonian (1996), a aplicação da teoria e método estabelecido por Santos (1979) pode se dar além do âmbito nacional, sendo possível estudos pautados no contexto estadual, regional e, conforme têm-se paulatinamente demonstrado, no âmbito das pequenas cidades. 0 autor citado inclusive aplicou o método em questão a fim de estudar a região industrial de Santa Catarina ${ }^{7}$.

Essa abrangência da teoria se faz realizável porque se em um dado país há diferenças de desenvolvimento histórico, o mesmo se dá em estados e regiões. Se não há sociedade geral, deve-se entender que há sociedades existentes sob um dado momento histórico. A partir de então, o método vem sendo utilizado por diversos pesquisadores, em especial, no âmbito da geografia humana, em busca de uma análise que contemple as problemáticas atreladas às especificidades de cada sociedade em determinado momento histórico.

Por outro lado, Corrêa (2000) propõe a aplicação da Formação Socioespacial como uma categoria de análise aplicável ao estudo das redes urbanas, as quais mostram-se um recorte geográfico para a compreensão da pequena cidade. Para Corrêa (2000) o entendimento dos elementos que articulam a rede urbana remete à compreensão da Formação Socioespacial na medida que uma rede urbana pode apresentar elementos das várias formações espaciais as quais esteve relacionada com o decorrer do tempo.

Conforme o autor, pode-se entender a rede urbana a partir dos tipos de Formação Socioespacial, qual seja; a gênese dos centros urbanos, decorrente das grandes ou pequenas propriedades rurais e $o$ processo de inserção das cidades na rede, em razão das transformações estruturais que as pequenas ou grandes propriedade podem ter passado, oriundas de processos econômicos diversos e, influenciados por fatores externos.

Portanto, uma vez que, conforme demonstrou Mamigonian (1996), a Formação Socioespacial de Milton Santos, associada ao elemento econômico, ou FESE, mostra-se plausível para a aplicação nas mais diversas escalas de análise, consideramos que a mesma pode ser aplicada no âmbito das pequenas cidades.

\section{5-Considerações finais}

\footnotetext{
${ }^{6}$ Grupo de Pesquisa Formação Sócio-espacial - Mundo/Brasil/Regiões. Maiores informações disponíveis em: http://geografiaeconomicaesocial.ufsc.br/teses-e-dissertacoes-g-p-formacao-socioespacial-mundo-brasil-e-regioes/ ${ }^{7}$ Do mesmo modo, Espíndola (1997) apontou a possibilidade da utilização dos conceito e método da Formação Socioespacial, quanto ao estudo de atividades industriais.
}

Para0nde!?, Porto Alegre, v.11, n.1, p.09-16, 2019. http://seer.ufrgs.br/paraonde

Edição Especial: "Geografia e transformações socioespaciais: dinâmicas agrárias e políticas do desenvolvimento regional" 
No presente trabalho inserimos a discussão conceitual e metodológica da Formação Socioespacial de Santos (1979), considerando os apontamentos de Mamigonian (1996) no tocante ao fato de estudar-se uma área de abrangência diferente da escala nacional, originalmente defendida por Santos (1979), uma vez que os aspectos econômicos certamente diferem no território brasileiro, fazendo sentido afirmar que há diferentes formações socioespaciais nesse país.

Uma vez que o conceito discutido remete à evolução diferencial das sociedades, mostra-se possível entender diferenças econômicas e sociais também no âmbito local, portanto, relativo às pequenas cidades, justificando a inserção dessa categoria de análise quanto ao estudo das mesmas, considerando para tal, o recorte geográfico da rede urbana.

Portanto, a partir das considerações de Mamigonian (1996), pode-se entender que a Formação Socioespacial deixa de estar atrelada meramente ao recorte geográfico Estado-Nação, podendo estar ligada a outros recortes geográficos, uma vez que as diferenças entre os espaços, oriundas de aspectos econômicos resultam em diferentes formações socioespaciais podendo pensar-se essas diferenças também no âmbito local, referente, portanto, à pequena cidade.

\section{6-Referências}

AMORIM FILHO, O. SERRA, R. V. Evolução e perspectivas do papel das cidades médias no planejamento urbano e regional. In: ANDRADE, T. A.; SERRA, R. V. (org.) Cidades médias brasileiras. Rio de Janeiro: IPEA, p.1-34, 2001.

ASALIN, Gilmar Aparecido. Gênese e dinâmica de três cidades na rede urbana de Maringá: Paranavaí, Nova Esperança e Nova Aliança do Ivaí. Tese (Doutorado em Geografia). Universidade Estadual de Maringá, Maringá, 303 f, 2015.

BACELAR, Winston Kleiber de Almeida. Pequena cidade: uma caracterização. V Encontro de Grupos de Pesquisa "agricultura, desenvolvimento regional e transformações socioespaciais. UFSM, Santa Maria, 2008.

BESSA, Kelly Cristine Fernandes. A dinâmica da rede urbana no Triângulo Mineiro: convergências e divergências entre Uberaba e Uberlândia. 2007. Tese (Doutorado em Geografia). Universidade Federal do Rio de Janeiro. 347 p.

CHOLLEY, André. Observações sobre alguns pontos de vista geográficos (part. 1). Boletim Geográfico. Rio de Janeiro: IBGE, n.179, p. 139-145. 1964a.Disponível em. <http://biblioteca.ibge.gov.br/visualizacao/periodicos/19/bg_1964_v22_n179_mar_abr.pdf> Acesso em 05/02/2017.

Observações sobre alguns pontos de vista geográficos (part. 2). Boletim Geográfico. RJ: IBGE, n.180, p.267-276. 1964b.

CHRISTOFOLETTI, Antônio. Perspectivas da Geografia. São Paulo: Difel, 1985, 318 p.

CORRÊA, Roberto Lobato. A rede urbana. São Paulo: Ed. Ática, 1989, 96 p.

Rede urbana e formação espacial - uma reflexão considerando o Brasil. Território, Rio de Janeiro, a. 5, n.8, p.121-129, jan. / jun, 2000.

Trajetórias geográficas. Rio de Janeiro: Bertrand Brasil, 2001.

ENDLICH, Ângela Maria. Pensando os papéis e significados das pequenas cidades. 2006. Tese (Doutorado em Geografia). Universidade Estadual Paulista "Júlio de Mesquita Filho, Presidente Prudente - SP, $505 \mathrm{p}$.

ESPÍNDOLA, C.J.; SILVA, M.A. da. Formação Sócio-Espacial: um referencial aos estudos sobre industrialização (notas). Experimental, São Paulo, n. 3, p. 61-67, setembro, 1997.

Para0nde!?, Porto Alegre, v.11, n.1, p.09-16, 2019. http://seer.ufrgs.br/paraonde

Edição Especial: "Geografia e transformações socioespaciais: dinâmicas agrárias e políticas do desenvolvimento regional" 
FRESCA, Tânia Maria. Transformações na rede urbana do Norte do Paraná: Estudo comparativo de três centros. 2000, 436f. Tese (Doutorado em Geografia Humana). Faculdade de Filosofia Letras e Ciências Humanas, Universidade de São Paulo, São Paulo.

2010.

Rede urbana e divisão territorial do trabalho. Revista Geografia. Londrina: v. 19 n. 2,

GEIGER, Pedro Pinchas. Evolução da Rede Urbana Brasileira. Rio de Janeiro: Instituto Nacional de Estudos Pedagógicos, 1963.

HOBSBAWN, Eric. Formações Econômicas Pré-Capitalistas de Karl Marx. Rio de Janeiro: Paz e Terra, 1985, $138 \mathrm{p}$.

IBGE. Sinopse do Censo Demográfico 2010.

Disponível em:

<http://www.censo2010.ibge.gov.br/sinopse/index.php?uf=35\&dados=1>

Acesso em 20/04/2016.

IPEA (INSTITUTO DE PESQUISA ECONÔMICA APLICADA). Caracterização e Tendências da Rede Urbana do Brasil. (Coleção Pesquisa, 3v), Brasília: IPEA; Rio de Janeiro: IBGE Campinas: UNICAMPIE/NESUR; IPEA; IBGE, 2000.

LENCIONE, Sandra. Observações sobre o conceito de cidade e urbano. GEOUSP - Espaço e Tempo, São Paulo, № 24, pp. 109 - 123, 2008.

LÊNIN, V.I. O desenvolvimento do capitalismo na Rússia: O processo de formação do mercado interno para a grande indústria. São Paulo: 1982.

LOPES, Diva Maria Ferlin. Revista Bahia Análise \& Dados (Cidades: Conceitos, Processos e História, p.395-412), Salvador, Superintendência de Estudos Econômicos e Sociais da Bahia, v. 19, n. 2, jul. / set. 2009.

MAGNANI, Ruth L.C. As cidades de Santa Catarina: base econômica e classificação funcional Revista Brasileira de Geografia, 33(1), 1971.

MAMIGONIAN, A. A Geografia e "A Formação Social como Teoria e como Método". In: SOUZA, M. A. A. de. (Org.) Mundo do cidadão, um cidadão do mundo. São Paulo: Hucitec, 1996, p.198-206.

MARX, K. O capital. São Paulo: Abril Cultural, 1983. v. 1.

; ENGELS, F. A ideologia alemã. São Paulo: Martins Fontes, 1998.

OLIVEIRA, Bianca Simoneli, SOARES, Beatriz Ribeiro. Cidades locais do triângulo mineiro e Alto Parnaíba/MG. In Revista Caminhos da Geografia, v.3, no5, p.52 - 72, 2002.

SANTOS, Milton. Sociedade e espaço: A formação social como teoria e como método. Espaço e sociedade. Petrópolis: Vozes, 1979. p. 9-27.

SERENI, Emílio. De Marx a Lenin: la categoria de "formación económica - social". Economia y Ciencias Sociales, Caracas, v. 13, p. 5-53, 1971.

VEIGA, José Eli da. Cidades imaginárias: O Brasil é menos urbano do que se calcula. São Paulo: Universidade de São Paulo, 2002, 304 f. 